\title{
Exercising restraint: autonomy, welfare and elderly patients
}

\author{
Susan Dodds Department of Philosophy, University of Wollongong, NSW, Australia
}

\begin{abstract}
Despite moves to enhance the autonomy of clients of health care services, the use of a variety of physical restraints on the freedom of movement of frail, elderly patients continues in nursing homes. This paper confronts the use of restraints on two grounds. First, it challenges the assumption that use of restraints is necessary to protect the welfare of frail, elderly patients by drawing on a range of data indicating the limited efficacy of restraints. Secondly, it argues that the duty to respect individual autonomy extends to a duty to respect the autonomy of patients who are elderly, frail and living in nursing homes.
\end{abstract}

The use of mechanical restraints to limit the freedom of individuals poses a great threat to personal dignity. People whose freedom is reduced through the use of restraints often become agitated, angry and, eventually, resigned to their loss of freedom. ${ }^{1-3}$ Testimony of patients who have been so restrained reveals the sense of loss of personal integrity and dignity which accompanies this loss of freedom. Evans and Strumpf quote two patients' experiences of restraint in hospital. A 72-year-old man said: "I felt like I was a dog and cried all night. It hurt me to have to be tied up. I felt like I was nobody, that I was dirt. It makes me cry to talk about it.... The hospital is worse than a jail". ${ }^{2}$ An 84-year-old woman recalled her experience this way: "I don't remember misbehaving, but I may have been deranged from all the pills they gave me. Normally, I am spirited, but I am also good and obedient. Nevertheless, the nurse tied me down, like Jesus on the cross, by bandaging both wrists and ankles.... It felt awful, I hurt and I worried, 'What if I get leg cramps; what will I do then if I can't move?' It was miserable ... and an awful shock... Because I am a cooperative person, I felt so resentful. Callers, including men friends, saw me like that and I lost something; I lost a little personal prestige. I was embarrassed, like a child placed in a

\section{Key words}

Aged care; mechanical restraints; autonomy; consent; competence. corner for being bad.... I haven't forgotten the pain ${ }_{N}^{N}$ and indignity of being tied". ${ }^{2}$

It is not surprising that health professionals $\vec{\sigma}$ considering whether to use mechanical restraints to limit the actions of elderly patients are often deeply distressed by the prospect. Those who have to make $\vec{C}$ such decisions may feel themselves confronted by two conflicting moral obligations: the duty to protect ${ }^{\Phi}$ those in their care from harm and the duty to respect $\overrightarrow{0}$ the autonomy of other persons. This paper argues $\&$ that justifications for the use of restraints based on the duty to protect elderly patients from harm are much weaker than many who rely on them may hope, in light of empirical evidence and a careful articulation of "harm". Moreover, it argues that the duty to respect an individual's remaining autonomy persists, even after the individual ceases to be legally응 competent. The imposition of physical restraints on paternalistic grounds, thus, has very limited justifica- $-\frac{\overrightarrow{0}}{0}$ tion. Further, the imposition of restraints in order to protect third parties, such as health care staff or other patients, is rarely justified. Finally, while in the $\frac{}{\sigma}$ United States restraints are frequently applied to 3 . protect nursing homes from litigation in the event of a fall or accident, ${ }^{4-6}$ those medico-legal issues are not $₹$ addressed here, in part because litigation should be응 informed by ethics, rather than ethics responding to litigation.

To clarify what I mean by restraints: restraints are any intentionally placed impediment to another's \% freedom of action. For older patients in nursing $N$ homes these impediments may include mechanical ${ }_{\mathcal{C}}$ restraints, for example vest, pelvic or waist restraints 0 which are attached to standard chairs, wheelchairs $x$ or to geriatric recliner-chairs and raised side-rails on hospital beds (with or without ankle and wrist $\stackrel{\mathcal{P}}{+}$ bandages tied to them); and the use of locked doors 0 and barred windows to restrict the movement of ${ }_{\overrightarrow{0}}^{-}$ patients. Chemical restraints - the use of psy- $\stackrel{\mathbb{Q}}{\stackrel{\mathrm{O}}{0}}$ chotropic drugs where there is no recorded diagno- $\overrightarrow{\mathbb{D}}$ sis of mental disorder - are also used to reduce $\frac{\Omega}{\sigma}$ patients' desire to move about. ${ }^{7}$ As the use of chemical restraints raises issues which fall outside the scope of this paper, this discussion is restricted to the use of mechanical restraints in nursing homes. 
Restraints may be placed on a person with her or his consent. For example, a woman who has cerebral palsy and is unable to hold herself in an upright sitting position may choose to have her freedom of movement restrained so that she may engage in various activities which she would otherwise be unable to do. Alternatively, a man can be bound by a waist restraint to his chair without his consent and against his will. My concern, here, is whether a policy of routine use of mechanical restraints in geriatric care without consent is morally justified.

None of us would think it morally justifiable to have others bind us to our chairs, to imprison us against our will, without very good reasons. Given that use of restraints limits personal freedom in a way which we would usually think reprehensible, the onus must be on those who advocate use of restraints to establish the justifiability of their use. Many sincere health professionals working in nursing homes would defend limited use of mechanical restraints on the grounds that the restraints are required to protect their patients from harm. Their argument might be of the following form. A special relationship exists between residents of nursing homes and those who have responsibility for their care. This special relationship gives rise to a moral duty on the part of the care-givers to protect those in their care from harm. Frail, elderly patients may sometimes lose their balance or become confused and disoriented and, as a result, risk harming themselves or others unless their movements are restricted. Thus, in certain circumstances, health professionals are morally obliged to place mechanical restraints on patients to protect them from harm.

This argument needs to be filled out to be at all useful in practice. We would need to know what harms are supposedly protected against by use of restraints and how serious or probable those harms need to be before application of restraints is justified. Further, we would need to know how strong the moral duty to protect those in one's care from harm is and how it compares with other duties (such as the duty to respect autonomy), which health care workers may have. When we examine some of the assumptions implicit in this defence of the use of restraints we find that this argument would only justify very limited use of restraints.

What harms are being prevented by use of restraints? Harms which restraint use is intended to avoid include: physical injury such as stumbling and breaking a hip (with the attendant grave effects on older patients); falling out of bed or a chair; risks of physical harm associated with wandering; and harms associated with failing to receive adequate treatment. ${ }^{8}$ Sometimes restraints are used in the hopes they will reduce psychological harms such as agitation, anxiety about falling out of bed, confusion which may result from wandering, etc. Some of these harms can be serious, even fatal, and restraints may serve to reduce them, but we must also consider whether restraints are effective at protecting against these harms, whether there are equivalent harms associated with use of restraints and whether effective alternatives to restraints are available.

Empirical research has indicated there is little evidence to suggest that restraints are effective ${ }^{6}$; various authors cite as evidence that restrained residents in a nursing home setting exhibited the same, or more agitated, behaviours than unrestrained residents ${ }^{3}$; that the use of bedrails is not effective at preventing falling out of bed in acute hospital settings ${ }^{3}$; "that the risk of injury from falls out of bed actually increases when restraints are applied and that restraints do not remove risk of injury" ${ }^{5}$; and that previously restrained nursing home residents experience no greater incidence of serious falls once their restraints are removed and, while they experience more non-serious falls than when they were restrained, they experience no greater incidence of non-serious falls than those residents who have never been restrained. ${ }^{9}$ Further, two nursing homes which have never used restraints in their many years of service record "no more injuries from falls than do facilities that use restraints". ${ }^{\text {The evidence suggests }}$ that risk of some of the harms which use of restraints is intended to protect against may be increased by their use. Indeed, accidental death has been reported after patients have attempted to escape from beds or chairs while restrained. ${ }^{23}$

Further, there is a body of evidence to suggest that restrained older patients suffer other ill-effects from being restrained. Restrained patients "often suffer from chronic constipation, incontinence, pressure sores, loss of bone mass, muscle tone and the ability to walk independently". ${ }^{13}$ Other harms associated with restraint use include: skin abrasions, abnormal changes in body chemistry, basal metabolic rate and blood volume; lower extremity oedema, contractures, cardiac stress and reduced functional capacity. ${ }^{2}$ The psychological harms associated with restraint are also significant: mechanical restraint may contribute to sensory deprivation, disorganised behaviour, loss of self-image and dependency; restraint may "increase confusion or precipitate regressive behaviour and withdrawal" 2 ; agitation is often increased, ${ }^{8}$ as is anger and demoralisation of residents. ${ }^{3}$ It appears that regular use of one's limbs and intellectual capacities of the sort that occurs when a person moves about freely assists in the preservation of these abilities and of health more generally. ${ }^{10}$ All in all, while restraints are intended to protect against harm, they may actually contribute to reduced health. At the very least this empirical evidence gives us reason to question the efficacy of restraints and indicates that alternatives to restraints should be sought to avoid the health risks posed by their use.

Evans has conducted cross-cultural research which indicates that refraining from use of restraints can be consistent with good health practice. ${ }^{411}$ This study points out the differences between American 
and Scottish nursing home staff in their attitudes towards the use of restraints. In Scotland, restraints are rarely used and it is accepted that while there are certain risks associated with unrestrained patients moving about, taking these risks is justified by respect for patients' autonomy and awareness of the benefits of continued mobility. ${ }^{411}$

Blakeslee's account of her nursing experience ${ }^{1}$ describes some alternative ways of protecting older patients from harm that she has developed in nursing home settings. She has been involved with two nursing homes in which restraints have never been used. Rearrangement of ward design, physical and behavioural therapy, and cooperation amongst all staff made it possible to protect patients from harm without depriving them of their freedom. ${ }^{1}$

A policy of justified restraint use must involve an assessment of the risk of harm posed by the absence of restraint as compared with the risk of harm posed by the imposition of restraints. This assessment must attend to both the seriousness of the harm and the probability of the harm occurring. A very low probability of a serious injury occurring if no restraints are imposed, may well be outweighed by a very high probability of less serious injury occurring if restraints are used. The degree to which alternatives to restraint reduce the probability of harm occurring must also be assessed.

The availability of alternatives will frequently depend on resources, attitudes and policies of health professionals, institutions and governments. Nonetheless, whoever claims that restraints are required to protect those in nursing home care from harm should be prepared to examine the empirical evidence concerning the use or avoidance of mechanical restraints, in order to make a genuine assessment of the risks of harm to those who would be restrained.

Although harms to health are the most frequently cited (and most easily tabulated) in the literature, the relative harms to physical and emotional health risked by restraint use or abeyance are not the only kinds of harm at stake. To be deprived of freedom and to have one's capacity for self-determination limited without consent are, in themselves, great harms - or simply wrongs - to individuals, even if done from a worthy motive. As the testimonials above imply, use of restraints threatens our sense of ourselves as persons, and may lead to a loss of self-respect. To feel like "a dog", "a nobody", "dirt", or to suffer loss of personal dignity are surely indications that the debate concerning use of restraints is not simply about protecting patients from harms to their health, but also about treating patients of all ages as persons worthy of respect. Imposing restraints on a person without consent may very well indicate a lack of respect for the patient as a person, a moral agent who has an interest in his or her own welfare and freedom.

The past twenty years have seen a shift in emphasis in health care from a strongly paternalistic approach to greater concern and respect for the personal autonomy of patients. No longer can health care workers assume $\stackrel{\text { T) }}{=}$. that the sole issue at stake in health care is the health ${ }^{\text {? }}$. of the patient. The language of patients' rights and self-determination has permeated medical schools $\frac{\text { की }}{2}$ nursing faculties, and health care institutions. Whenc one is assessing the merits of restraints, one musto count all harms to a person's interests. Some of those interests are in health and physical well-being, but others are interests in freedom, personal dignity, $\infty$ autonomy and respect by others.

Patients in nursing homes are very often peoplewho were active in pursuing various interests for most $\vec{\omega}$ of their lives. They have made autonomous choices? about their careers, their families, their values, their health and the course of their lives. These choicesin would often have involved taking risks. For example, $\omega$ in deciding to marry a person risks hurting her or himself deeply if the marriage fails; rock-climbing risks serious physical harm, perhaps even death, and? investing all one's savings in one particular venturemay lead to financial ruin. The choices made and the risks taken by these people throughout their liveso reflect the interests and the values which are part of $-\overrightarrow{0}$ their identity as autonomous individuals. There is no\& reason to believe that when people become older and less able to live fully independently, they lose allo interests beyond protection of their health. On the contrary, many people, despite sometimes experiencing lapses of memory or periods of confusion, have aी clear view that life and health are just two values? among many and a firm idea of how they want to liveo out the rest of their lives. ${ }^{12} 13$

Nursing homes are designed to look after the health interests of those in their care and health care professionals in such homes have special responsibil ities to protect the health of those in their care. Such ${ }^{\mathbb{D}}$ professionals also have immense control over the lives of patients, who are often entirely dependent on nursing home staff in order to pursue any of their interests. From this disproportionate power also arises the special responsibility of nursing home staff to respect the autonomy of patients. They may have to look beyond conventional practices to ensure that their policies do respect the dignity, freedom ands autonomy of their patients.

That a person is frail and unsteady on her or his feet does not render her or him incapable of making autonomous choices, even if the frailty and unsteadiness increases the risk that she or he will be harmed? Further, the loss of some mental functioning may be? good reason for limiting a person's responsibilities concerning her or his affairs (for example, the appointment of a guardian responsible for managing the person's financial affairs). But to say that a persorid lacks sufficient capacity to exercise autonomy inf these areas is not to say that she or he lacks autonomy outright. Thus, a person may lack legal competence and yet still be a person whose autonomy ought to be respected. The ability to understand or retain suffio. cient information to make complex choices abou 
treatment (that is competence to consent to that treatment), may be lost without loss of all competence to make choices or to express preferences. Autonomy develops by degrees, so too it can diminish over time. In some cases respect for autonomy requires that health professionals act on the previously articulated preferences and attitudes of a person who is no longer able to express her or his autonomy. In such cases a guardian may be able to articulate the autonomous interests of a patient.

Neither nursing home residents, nor those outside nursing homes, have a moral obligation to preserve their own health above all else. Residents are owed the respect due to persons: they are entitled to have their interests respected even if pursuit of their interests means that they might hurt themselves. To deprive a person of freedom of action without consent is, prima facie, a violation of the duty to respect persons. If use of restraints is proposed, then consent from either the patient or from the patient's proxy (who is charged to act in the interests of the patient), must be sought and granted. Such consent should only be given where adequate information is offered about the nature and duration of the restraint, the reason for its use and the risks associated with the use of restraint as opposed to absence of restraint (or other alternatives).

Where it is genuinely the best available course of care, use of constraints may be justified without the patient's consent if the patient lacks sufficient autonomy to make any kind of choice, or to recognise in very basic terms the nature of her or his choice. However, her or his guardian or proxy must consent to the use of restraints in light of the guardian's knowledge of the patient and the evidence given to support restraint use.

Some may argue that use of restraints on a patient, without consent, can be justified to protect other patients and staff from harm. One question to be asked is whether this kind of restraint is proposed as protection or as punishment. ${ }^{8}$ It is generally accepted that the only authority that can legitimately deprive adults of their liberty, as punishment, is the state (through the court system) and, thus, that it would be illegitimate for nursing home staff to deprive individuals of their liberty as a form of punishment. If restraints are to be used as protection for others, one must ask on what grounds the other patients or staff are believed to be at risk. Surely the test for use of restraints in these cases must take into account the risk of harm posed by restraint to the person to be restrained as compared to the risk of harm posed to the staff or other patients. If nursing home staff have no business using restraints as punishment (as it would be a form of illegal and unjustified imprisonment), then the harm which is to be avoided must be at least as great as the harm which is risked through use of restraints, in order to justify this limitation of freedom.

Two weaknesses in the standard defence of the use of mechanical restraints on elderly nursing home patients have been uncovered: firstly, empirical evidence suggests that restraints may cause the kinds of harm they are intended to protect against; secondly, restraints frequently involve an unjustified limitation of the autonomy of patients. This is not to claim that all possible arguments for restraint use have been defeated. Rather, the onus is placed firmly on those who wish to restrain elderly patients to provide adequate justification for their decision. Thorough assessment of the harms which use of restraints may avoid or cause in a particular case, and the requirement of consent to use of restraints, should serve to reduce risk of harm while protecting the freedom and autonomy of elderly patients. A challenge is made, then, to nursing home administrators and staff to attempt to avoid the need for restraints by taking on the task of assessing why a particular patient wanders, or sleeps poorly, or poses a risk to others. Further effort should go into developing alternatives to use of mechanical restraints. Care for residents can be improved if the possibilities for safe, restraint-free nursing homes which protect personal freedom are thoroughly examined.

Susan Dodds, PhD, is Senior Lecturer in Philosophy, Department of Philosophy, University of Wollongong, NSW, Australia.

\section{References}

1 Blakeslee JA. Speaking out: untie the elderly. American fournal of Nursing 1988; 88: 833- 4.

2 Evans LK, Strumpf NE. Myths about elder restraint. Image: Fournal of Nursing Scholarship 1990; 22: 124-8.

3 Moss RJ, La Puma J. The ethics of mechanical restraints. Hastings Center Report 1991; 21: 22-5.

4 Anonymous [editorial]. Cotsides - protecting whom against what? Lancet $1984 ; 2$ : 383-4.

5 Collopy B, Boyle P, Jennings B. New direction in nursing home ethics. Hastings Center Report (special supp) $1991 ; 21: 3-15$

6 Evans LK, Strumpf NE. Tying down the elderly. Fournal of the American Geriatrics Society 1989; 37: 65-74.

7 Jencks SF, Clauser SB. Managing behaviour problems in nursing homes. Fournal of the American Medical Association 1991; 265,4: 502-3.

8 Tinetti M, Liu W, Marottoli R, Ginter S. Mechanical restraint use among residents of skilled nursing facilities. Fournal of the American Medical Association 1991; 265: 468-71.

9 Ejaz FK, Jones JA, Rose MS. Falls among nursing home residents. Fournal of the American Geriatrics Society 1994; 42: 960-4.

10 Hogue CC. Falls and mobility late in life. Fournal of the American Geriatrics Society 1984; 32: 82-5.

11 Evans L. Restraint use with the elderly patient. Nursing research and clinical management of Alzheimer's disease proceedings, Minneapolis: University of Minnesota, 1989: 41-57.

12 Schaffer A. Restraints and the elderly. Canadian Medical Association fournal 1985; 132: 1257-60.

13 Agich GJ. Reassessing autonomy in long term care. Hastings Center Report 1990; 20: 12-7. 